\title{
Simplified Mathematical Model for Effects of Freezing on the Low-Temperature Performance of the Lead-Acid Battery
}

\author{
K. S. Gandhi, ${ }^{\text {a,z }}$ A. K. Shukla, ${ }^{\text {b,c, }, \mathrm{z}}$ S. K. Martha, ${ }^{\mathrm{b}}$ and S. A. Gaffoor ${ }^{\mathrm{d}}$ \\ ${ }^{a}$ Department of Chemical Engineering and ${ }^{b}$ Solid State \& Structural Chemistry Unit, \\ Indian Institute of Science, Bangalore 560 012, India \\ ${ }^{c}$ Central Electrochemical Research Institute, Karaikudi 630006, India \\ ${ }^{d}$ NED Energy Limited, Hyderabad 500082, India
}

Discharge periods of lead-acid batteries are significantly reduced at subzero centigrade temperatures. The reduction is more than what can be expected due to decreased rates of various processes caused by a lowering of temperature and occurs despite the fact that active materials are available for discharge. It is proposed that the major cause for this is the freezing of the electrolyte. The concentration of acid decreases during battery discharge with a consequent increase in the freezing temperature. A battery freezes when the discharge temperature falls below the freezing temperature. A mathematical model is developed for conditions where charge-transfer reaction is the rate-limiting step, and Tafel kinetics are applicable. It is argued that freezing begins from the midplanes of electrodes and proceeds toward the reservoir in-between. Ionic conduction stops when one of the electrodes freezes fully and the time taken to reach that point, namely the discharge period, is calculated. The predictions of the model compare well to observations made at low current density $(\mathrm{C} / 5)$ and at -20 and $-40^{\circ} \mathrm{C}$. At higher current densities, however, diffusional resistances become important and a more complicated moving boundary problem needs to be solved to predict the discharge periods.

(C) 2009 The Electrochemical Society. [DOI: 10.1149/1.3068391] All rights reserved.

Manuscript submitted September 14, 2008; revised manuscript received December 15, 2008. Published January 29, 2009.

The lead-acid battery was invented as early as 1859 by Raymond Gaston Planté. Today, it happens to be the most widely used storage battery for a range of applications, from powering bicycle headlights to electric vehicles. It offers several advantages: the highest cell voltage among aqueous electrolyte batteries, ability to operate over a wide range of temperatures, an acceptable energy efficiency of over $80 \%$, an acceptable level of charge retention, and nearly $100 \%$ recyclability of spent batteries. Predicting the performance of leadacid batteries is therefore of importance, and several models have been developed for this purpose. They take into account the finite rate of the charge-transfer reactions, and ohmic as well as diffusional resistances. To cite a few, Gu et al. ${ }^{1}$ and Nguyen and White ${ }^{2}$ developed a one-dimensional (1D) model; a two-dimensional (2D) model of lead oxide electrode was developed by Dimpault-Darcy et al.; ${ }^{3}$ Bernardi et al. ${ }^{4}$ developed a 2D model of the cell; nonisothermal effects were examined by Huang and Nguyen; ${ }^{5}$ and oxygenrecombinant cells were modeled by Bernardi and Carpenter ${ }^{6}$ and Newman and Tiedemann. ${ }^{7}$ These models can predict the discharge period of a battery once a cutoff voltage is specified. However, these models have focused on predicting the performance of the battery at normally encountered ambient temperatures. References (see, for example, Chapter 23 in Ref. 8 and the book by Bode ${ }^{9}$ ) do point to severely curtailed discharge periods when the battery is operated at temperatures well below the freezing point of water (i.e., $0^{\circ} \mathrm{C}$ ). The same is demonstrated by data on discharge at constant current density obtained in our laboratories and shown in Table I: The discharge period is reduced from $5 \mathrm{~h}$ at $25^{\circ} \mathrm{C}$ to $2.75 \mathrm{~h}$ at $-40^{\circ} \mathrm{C}$. As evident from the longer discharge period at $25^{\circ} \mathrm{C}$, the discharge period at low temperatures is reduced even though the battery still has a considerable amount of unreacted active materials. The objective of the present paper is to present a simplified model to explain the drastic reduction in discharge periods at low temperatures. A major reason for reduction is freezing of the electrolyte. Typically, a lead-acid battery is charged with $4.5 \mathrm{M}$ aq. $\mathrm{H}_{2} \mathrm{SO}_{4}$. The freezing point at this concentration is about $-50^{\circ} \mathrm{C}$. As the battery discharges, acid is consumed and, hence, its concentration decreases. Consequently, the freezing temperature increases. At some instant during discharge, the temperature at which the battery is being discharged will be less than the freezing temperature. At that instant, the electrolyte will

\footnotetext{
Electrochemical Society Active Member.

z E-mail: gandhi533@gmail.com; akshukla2006@gmail.com
}

freeze and ionic conduction comes to a halt. Consequently, the overpotential increases beyond the specified limit, arresting the discharge process.

We first show a simple calculation of the discharge period both to justify the relevance of the above explanation and to demonstrate the need for a detailed model. Consider discharge at a constant current density of $|I|$. Assume for the moment that the rate of charge transfer reaction controls the process and all other resistances are negligible. Thus, all parts of the battery are at identical conditions. In particular, the concentration of the acid in the battery is spatially uniform. Its temporal variation can then be predicted from stoichiometry as follows. The reaction occurring at the positive plate is

$$
\mathrm{PbO}_{2}(\mathrm{~s})+\mathrm{H}_{2} \mathrm{SO}_{4}+2 \mathrm{H}^{+}+2 \mathrm{e}^{-} \rightarrow \mathrm{PbSO}_{4}(\mathrm{~s})+2 \mathrm{H}_{2} \mathrm{O}
$$

and that at the negative plate is

$$
\mathrm{Pb}(\mathrm{s})+\mathrm{H}_{2} \mathrm{SO}_{4} \rightarrow \mathrm{PbSO}_{4}(\mathrm{~s})+2 \mathrm{H}^{+}+2 \mathrm{e}^{-}
$$

Thus, in the entire cell, a molecule of acid is consumed for each electron transferred. Let $L_{\mathrm{p}}, L_{\mathrm{n}}$, and $L_{\mathrm{r}}$ be the half thicknesses of the positive and negative electrodes, and thickness of the reservoir, respectively. Let $\varepsilon_{\mathrm{p}}, \varepsilon_{\mathrm{n}}$, and $\varepsilon_{\mathrm{r}}$ be the porosities of the positive and negative electrodes, and the reservoir, respectively. Stoichiometry dictates that

$$
\frac{d}{d t}\left(L_{\mathrm{p}} \varepsilon_{\mathrm{p}}+L_{\mathrm{n}} \varepsilon_{\mathrm{n}}+L_{\mathrm{r}} \varepsilon_{\mathrm{r}}\right) C=-3600 \frac{|I|}{F}
$$

where $|I|$ is the constant current density, $F$ is Faraday's constant, and $t$ is the time elapsed since discharge began, measured in hours. Neglecting the variation in the porosity of the electrodes due to discharge, this can be integrated to obtain

Table I. Observed and predicted discharge period at constant current density. Prediction of discharge period assuming instantaneous freezing occurs.

\begin{tabular}{lccc} 
Temperature $\left({ }^{\circ} \mathrm{C}\right)$ & 25 & -20 & -40 \\
\hline $\begin{array}{l}\text { Observed discharge } \\
\text { Period }(\mathrm{h})\end{array}$ & 5.0 & 3.25 & 2.75 \\
$\begin{array}{l}\text { Predicted discharge } \\
\text { period }(\mathrm{h})\end{array}$ & - & 2.2 & 0.8
\end{tabular}

period (h) 


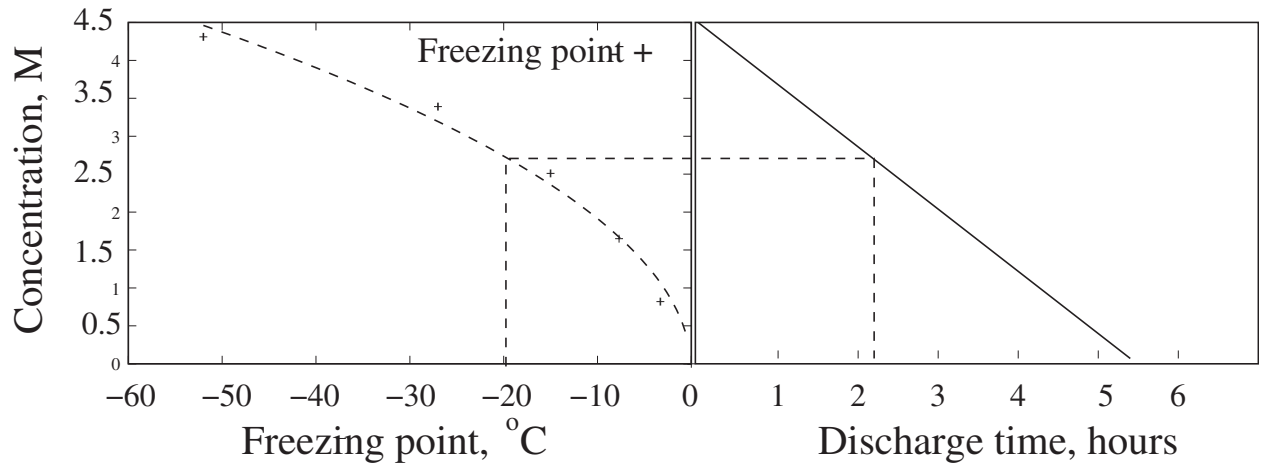

Figure 1. Prediction of discharge period assuming instantaneous freezing. Data on freezing points obtained from Ref. 8.

$$
|I|(3600 t)=\left(L_{\mathrm{p}} \varepsilon_{\mathrm{p}}+L_{\mathrm{n}} \varepsilon_{\mathrm{n}}+L_{\mathrm{r}} \varepsilon_{\mathrm{r}}\right)\left(C_{\mathrm{ref}}-C\right) F
$$

where $C_{\text {ref }}$ is the initial concentration and $C$ is the concentration of acid at time $t$. Thus, concentration decreases linearly with time. Data on freezing temperatures against concentration have been given in Ref. 8. From this data, the instant of time at which the freezing temperature equals the discharge temperature can be determined as shown in Fig. 1. Concentration values at freezing point are plotted against freezing temperature on the left side of Fig. 1. Concentration at any instant during the discharge period calculated from Eq. 3 is plotted against time on the right side of Fig. 1. Design details of the battery are given in the Appendix. The current density used is $|I|$ $=0.0068 \mathrm{~A} / \mathrm{cm}^{2}$ corresponding to $\mathrm{C} / 5$. Suppose the temperature of discharge is $-20^{\circ} \mathrm{C}$. By drawing a vertical line on the left-hand side of Fig. 1 from $-20^{\circ} \mathrm{C}$, as shown in Fig. 1, the concentration at which the freezing point corresponds to the discharge temperature is found to be $2.75 \mathrm{M}$. The instant during discharge when this concentration is reached is found by drawing a horizontal line from this concentration to intersect with the line on the right-hand side of Fig. 1. It is found to be $2.2 \mathrm{~h}$. Porous electrodes have a large solid surface area on which nucleation can occur. Hence, it is reasonable to assume that significant supercooling is not required for solidification to occur. Thus, even the slightest decrease in concentration below $2.75 \mathrm{M}$ should lead to the formation of ice. Because the entire battery is at uniform condition, ice should form throughout the battery. Even if a thin coat of ice forms on the solid surfaces of the electrodes, it would soon cover the whole active surface area. In both ways, ionic conduction should cease and discharge would be arrested. Thus, the discharge period should correspond to the time required for the concentration to reach the value when freezing occurs at the temperature of discharge. It therefore is $2.2 \mathrm{~h}$ for the example being considered. Predictions made in this manner are tabulated in Table I. The calculations do show a drastic reduction in the discharge periods, lending credence to the explanation. But they are quite low in relation to observations, thereby demonstrating the need for a more detailed model. In this paper, we focus on predicting the discharge period at small current densities and discuss the implications of relaxing this assumption later.

\section{Experimental}

The $2 \mathrm{~V} / 40$ Ah (C/10-rate) absorptive glass mat (AGM)-valueregulated lead-acid (VRLA) cells were assembled by stacking three positive plates (each of $14 \mathrm{Ah}$ ) and four negative plates (each of $12 \mathrm{Ah}$ ). Positive and negative plates in these cells were separated by placing $2 \mathrm{~mm}$ of AGM separator obtained from Nippon Sheet Glass Co., Japan. The plates were strapped with polythene bands and connected to their respective lugs. Before placing them in a polypropylene container, the cells were filled with $360 \mathrm{~mL}$ of $1.25 \mathrm{sp}$. gr. aqueous sulfuric acid and kept for $2 \mathrm{~h}$ for electrolyte soaking. Prior to acid filling, each cell was leak tested up to 7 psi. The cells were made positive limited to facilitate oxygen recombination at the negative plates. The cells were subjected to formation and subsequently filled with $100 \mathrm{~mL}$ of gelled electrolyte obtained by ultra- sonically mixing $4.5 \mathrm{M}$ aqueous sulfuric acid with $5 \mathrm{wt} \%$ silica. The hybrid-VRLA cells thus assembled were kept for $\sim 24 \mathrm{~h}$ for the gel to form fully and settle. As the gel stiffens, it shrinks and leads to formation of numerous microfine cracks. All the cells were formed using a Bitrode model LCN cycle-life tester interfaced to a data-acquisition system. Subsequently, the cells were subjected to formation. Six cells separated by $2.5 \mathrm{~mm}$ plastic casing material were connected in series to form a battery. The battery was tested at varying temperatures in temperature-controlled chambers. A constant current density of $0.0068 \mathrm{~A} / \mathrm{cm}^{2}$ (corresponding to $\mathrm{C} / 5$ ) was employed.

\section{Model}

Diffusion and electrolytic conduction have been assumed to be very fast in calculating the values shown in Table I. This could be a reason for the disagreement between predictions and observations. One more is the assumption of instantaneous freezing. We argue below that, though transport processes are fast, even the very marginal concentration gradients that exist will cause freezing to occur gradually from one end. This is the effect that needs to be accounted for to explain the major part of the deviation between the calculated values and observations shown in Table I.

Battery model equations. - Equations for predicting the performance of the battery are written using a 1D macrohomogeneous model. The equations are similar to those given earlier by Gu et al., Bernardi et al., ${ }^{4}$ and others. We do not consider recombination reaction and neglect the porosity changes caused by the difference in the density of the products and reactants. The latter can easily be corrected if a numerical scheme is followed to solve the equations. First, we have the Butler-Völmer equation to describe the rate of the charge-transfer reaction

$$
S=a i_{\mathrm{o}}^{\mathrm{ref}}\left(\frac{C}{C_{\mathrm{ref}}}\right)^{\gamma}\left[e^{\alpha\left[\phi_{\mathrm{s}}-\phi-E^{o}(C)\right] F / R T}-e^{-\beta\left[\phi_{\mathrm{s}}-\phi-E^{o}(C)\right] F / R T}\right]
$$

Here, $i_{o}^{\text {ref }}$ is the exchange current density at $C_{\text {ref }}$ and is a function of temperature, $a$ is the active surface area per unit volume, $C$ is the acid concentration while $C_{\text {ref }}$ is its initial value, $\phi_{\mathrm{s}}$ and $\phi$ are the potentials in the solid and fluid phases, respectively, and $E^{o}$ is the equilibrium potential at the prevailing local concentration. Various values have been reported for $\gamma$. We take $\gamma=1$ in the positive plate and $\gamma=0$ in the negative plate. We used $\gamma=0$ for the negative electrode, a value used in literature. ${ }^{4,6,7}$ We will later examine the influence of the values used. Charge balance in the solid phase combined with Ohm's law gives an equation for the potential in the electrode phase

$$
0=\frac{\partial}{\partial x}\left(\sigma_{\mathrm{eff}} \frac{\partial \phi_{\mathrm{s}}}{\partial x}\right)-S
$$

Charge balance combined with constitutive equations for species flux ${ }^{18}$ gives an equation for the potential in the electrolyte phase 


$$
0=\frac{\partial}{\partial x}\left(\kappa_{\mathrm{eff}} \frac{\partial \phi}{\partial x}\right)-\frac{R T}{F} \frac{\partial}{\partial x}\left(\kappa_{\mathrm{eff}} \frac{1-2 t^{+}}{C} \frac{\partial C}{\partial x}\right)+S
$$

Finally, we have the mass conservation equation for the acid

$$
\frac{\partial}{\partial t}(\varepsilon C)=\frac{\partial}{\partial x}\left(D_{\text {eff }} \frac{\partial C}{\partial x}\right)-K_{2} S
$$

where $K_{2}$ is the stoichiometric equivalent for charge transfer and acid consumed. The above set of equations needs to be written for the positive and the negative plates. $K_{2}$ is given by

$$
K_{2 \mathrm{p}}=\frac{2 t^{+}-3}{2 F} \text { and } K_{2 \mathrm{n}}=\frac{2 t^{+}-1}{2 F}
$$

for the positive and negative plates, respectively.

Simplifications.- As explained earlier, we anticipate formation and growth of ice phase sometime after discharge begins. In general, problems involving phase change lead to moving boundary value problems that must be solved numerically. In this paper, we seek simplifications to arrive at a simple but restricted solution that will give a bound for the discharge period. Newman and Tiedemann ${ }^{10}$ present scaling analysis of battery equations, which forms the basis for simplifications. The criteria for various simplifications are summarized below.

Consider discharge of a battery at a constant current density, $|I|$. Let $L_{\mathrm{c}}$ be the characteristic thickness of an electrode. Let $\kappa$ and $\sigma$ be the conductivities of the electrolyte and that of the electrode. Let $D$ be the diffusion coefficient of the acid. The overpotential due to ohmic losses can be neglected if both

$$
L_{\mathrm{c}}|I| \frac{F}{R T}\left(\frac{1}{\kappa}+\frac{1}{\sigma}\right) \ll 1 \text { and }(a i)_{\mathrm{o}} L_{c}^{2} \frac{F}{R T}\left(\frac{1}{\kappa}+\frac{1}{\sigma}\right) \ll 1
$$

are satisfied. Thus, if these criteria are met, $\phi_{\mathrm{s}}-\phi$ will not vary spatially in the positive and negative electrodes, though it can be different in the two electrodes. If $(a i)_{0} L_{\mathrm{c}} /|I| \ll 1$, Tafel kinetics can be assumed. If all three criteria are satisfied, then the ratio of the electrode thickness to the penetration depth is given by $f|I| L_{\mathrm{c}} / F D C$, where $f$ is the fraction of acid consumed in the electrode. If $f|I| L_{\mathrm{c}} / F D C \ll 1$, then the electrodes are thinner than the penetration depth and diffusional limitations are absent. Absence of diffusional resistance implies that the concentration of acid is uniform across the electrodes. We develop a model assuming $\phi_{\mathrm{s}}-\phi$ and $C$ are uniform across the electrodes, and use Tafel kinetics. We will later examine whether the criteria are met or not.

Each pair of electrodes in the battery, provided temperature is uniform, will behave similarly and it is sufficient to treat a reservoir sandwiched by one-half of a positive and one-half of a negative, for modeling purposes. With this simplification in mind, let us examine temperature gradients in the battery. The electrodes are porous, and the area of contact between the electrode and the electrolyte is large. Hence, the rate of heat exchange between them is rapid. It is then reasonable to assume that the electrolyte and electrode phases are at the same temperature (i.e., the temperature at any cross section is the same). If heat liberated in the battery is not removed efficiently, then temperature gradients will develop. Heat is liberated in the battery for two reasons: $(i)$ There are the " $|I|^{2} R$ " losses. Because the electrical conductivity is large, the heat liberation due to ohmic heating can be neglected. It is shown in the Appendix that, at the small current density used in experiments, the heat generation due to the overpotential caused by the charge-transfer reaction is also negligible. However, at large current densities, this might not be the case. (ii) Latent heat is liberated when freezing occurs, and this is important in the present context. Latent heat is fairly large, and temperature gradients can exist if its removal is slow. It is shown in the Appendix that temperature can rise by nearly $60^{\circ} \mathrm{C}$ under adiabatic conditions for the battery under consideration. The battery therefore cannot freeze until the latent heat is removed.

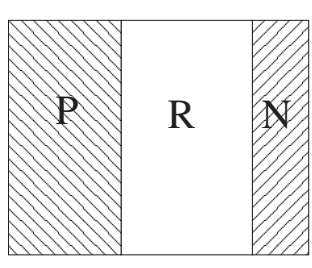

Initial state

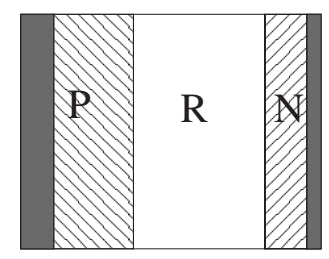

Freezing proceeds from outside

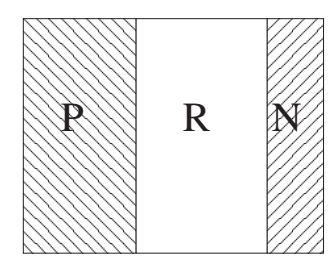

\section{Condition when freezing point is reached}

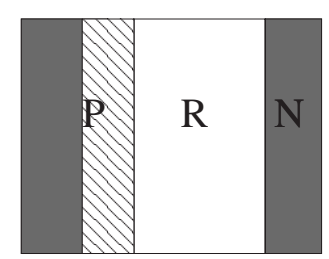

One electrode freezes completely, discharge halts
Figure 2. Schematic of the freezing process in a pair of half electrodes and reservoir in-between.

Let $C^{*}\left(T_{\mathrm{d}}\right)$ be the concentration at which freezing occurs at the discharge temperature, $T_{\mathrm{d}}$. Freezing begins in the electrodes when $C$ equals $C^{*}\left(T_{\mathrm{d}}\right)$. Because diffusion is being assumed to be fast, concentration gradients are negligible. However, very marginal concentration gradients will be present in the electrodes. The acid concentration falls in the electrodes as battery discharges, and acid diffuses from the reservoir into the electrodes. Hence, the concentration will be marginally lower in the center of each pair of electrodes and marginally higher in the reservoir in-between. Freezing temperature decreases with increasing acid concentration. Thus, the freezing temperature is marginally higher at the center of the electrode than inside the reservoir. In each cell, therefore, freezing will begin from the center of each pair of electrodes and proceed toward the reservoir in-between them. Referring to the experimental setup used, the middle cells can however freeze only when latent heat is removed through the adjoining ones and through the plastic walls. We therefore argue that freezing will begin in the end cells first and proceed toward the center of the battery. Now let us consider the situation in the end cells. The rate of heat removal from the end cells into the ambient is controlled by conduction resistances in the battery and its plastic casing and convective heat transfer from the exterior of the battery. We can conveniently combine the convective resistance with the conductive resistance of the plastic casing. In the Appendix, the thermal resistance of a pair of half electrodes and the reservoir is calculated to be $60 \mathrm{~K} \mathrm{~cm}^{2} / \mathrm{W}$, while that of a single wall of casing is $250 \mathrm{~K} \mathrm{~cm}^{2} / \mathrm{W}$. A cell has six such pairs and two walls. Thus, the resistance of the walls is greater by a factor of 1.4. Though this is not large, we assume that the temperature gradients are confined to the plastic casing. Hence, the temperature in the electrodes and electrolyte is uniform in the end cells. Accordingly, in the end cells, freezing will begin in the center of each electrode and proceed toward the reservoir in-between. A schematic of the gradual process of freezing is shown in Fig. 2.

As temperature is uniform, the concentration everywhere is nearly equal to the freezing concentration at the temperature prevailing. Hence, the freezing front will move toward the reservoir as acid is consumed. The rate of movement of the front is dictated by the rate of consumption of acid set by the current density. We initially assume that the heat removal is very efficient and that the cell is at the discharge temperature. We examine the effects of relaxing this assumption later.

The six cells of the battery are in series. Hence, when the end 
cells freeze, connectivity is broken and overpotential builds up to large values. Thus, it is only necessary to calculate the dynamics of the end cell under the assumptions listed earlier to predict the time of discharge of the battery.

Let us summarize the model. Freezing will begin from the center of each pair of electrodes in the end cells when the concentration reaches the value where freezing should occur at the discharge temperature [i.e. $\left.C^{*}\left(T_{\mathrm{d}}\right)\right]$. The time at which this happens can be calculated from Eq. 3 as shown earlier. Let it be denoted by $t_{\mathrm{o}}$. From then on, the concentration should remain constant at $C^{*}\left(T_{\mathrm{d}}\right)$. Thereafter, in each electrode, a layer of ice grows from the center toward the reservoir. The rate of growth is dictated by the rate of consumption of acid. Discharge will be arrested when one of the electrodes freezes completely. Let the time taken for one of the electrodes to freeze fully first be denoted by $t_{\mathrm{f}}$. The total discharge period is given by $t_{\mathrm{d}}=t_{\mathrm{o}}+t_{\mathrm{f}}$.

Calculation of discharge period.- The concentration and temperature at which freezing occurs are related through the phase diagram. Let $C^{*}(T)$ be the acid concentration in a solution that freezes at $T$. Let the ambient or the nominal discharge temperature be $T_{\mathrm{d}}$. Because ohmic heating as well as heat generated due to charge transfer are negligible, temperature of the battery remains constant at $T_{\mathrm{d}}$ until freezing begins. Thus, freezing will begin when the acid concentration falls to $C^{*}\left(T_{\mathrm{d}}\right)$ from its initial value of $C_{\text {ref. }}$.

Calculation prior to freezing.- As shown previously, the time required for the freezing concentration to be reached, $t_{0}$, can then be calculated from Eq. 3. It is given by

$$
t_{\mathrm{o}}=\frac{\left(L_{\mathrm{p}} \varepsilon_{\mathrm{p}}+L_{\mathrm{n}} \varepsilon_{\mathrm{n}}+L_{\mathrm{r}} \varepsilon_{\mathrm{r}}\right)\left(C_{\mathrm{ref}}-C^{*}\right) F}{3600|I|}
$$

The cell potential is given by $\left(\phi_{\mathrm{sp}}-\phi_{\mathrm{sn}}\right)$ where $\phi_{\mathrm{sp}}$ and $\phi_{\mathrm{sn}}$ are the potential of the positive and negative plates. The cell potential during this period can be calculated as follows. Charge balance gives

$$
\frac{d i}{d x}=S
$$

where $i$ is the local current density in the electrolyte phase of the electrodes. Because concentration and potentials are spatially invariant, integration of the above equation gives

$$
|I|=|S| L
$$

for both electrodes. Using Tafel kinetics in the above equation, we obtain the following for the positive plate

$$
\frac{|I|}{L_{\mathrm{p}}}=(a i)_{\mathrm{op}} \frac{C}{C_{\mathrm{ref}}} \exp \left\{\frac{-F\left[\phi_{\mathrm{sp}}-\phi-E_{\mathrm{p}}^{o}(C)\right]}{R T_{\mathrm{d}}}\right\}
$$

and

$$
\frac{|I|}{L_{\mathrm{n}}}=(a i)_{\mathrm{on}} \exp \left\{\frac{F\left[\phi_{\mathrm{sn}}-\phi-E_{\mathrm{n}}^{o}(C)\right]}{R T_{\mathrm{d}}}\right\}
$$

for the negative plate. Hence,

$$
\begin{aligned}
\phi_{\mathrm{sp}}-\phi_{\mathrm{sn}}= & -\frac{R T_{\mathrm{d}}}{F}\left[\log \frac{|I|}{(a i)_{\mathrm{on}} L_{\mathrm{n}}}+\log \frac{|I|}{(a i)_{\mathrm{op}} L_{\mathrm{p}}} \frac{C_{\mathrm{ref}}}{C}\right]+E_{\mathrm{p}}^{o}(C) \\
& -E_{\mathrm{n}}^{o}(C)
\end{aligned}
$$

The decrease in the cell potential, $\eta$, from the equilibrium value at the initial condition is given by

$$
\begin{aligned}
\eta= & E_{\mathrm{p}}^{o}\left(C_{\mathrm{ref}}\right)-E_{\mathrm{p}}^{o}(C)+E_{\mathrm{n}}^{o}(C)-E_{\mathrm{n}}^{o}\left(C_{\mathrm{ref}}\right) \\
& +\frac{R T_{\mathrm{d}}}{F}\left(\log \frac{|I|}{(a i)_{\mathrm{on}} L_{\mathrm{n}}}+\log \frac{|I|}{(a i)_{\mathrm{op}} L_{\mathrm{p}}} \frac{C_{\mathrm{ref}}}{C}\right)
\end{aligned}
$$

Calculation after freezing.- Now we proceed to calculate the time required for the first of the two electrodes to freeze fully. The thickness of ice formed in one-half of the positive electrode is denoted by $x_{\mathrm{p}}$. The same is $x_{\mathrm{n}}$ in the negative electrode. As the extent of reaction in the two is different, the thicknesses are expected to be different. The concentration of acid in the end cells must be equal to $C^{*}\left(T_{\mathrm{d}}\right)$ because it is being assumed that the contents are at the same temperature, $T_{\mathrm{d}}$. The phase diagram ${ }^{9}$ indicates that at freezing conditions, for concentrations up to $\sim 5.5 \mathrm{~mol} / \mathrm{L}$, acid is not present in the frozen phase (i.e., pure ice is in equilibrium with acid). Hence, mass balance gives

$$
C^{*} \frac{d}{d t}\left[\left(L_{\mathrm{p}}-x_{\mathrm{p}}\right) \varepsilon_{\mathrm{p}}+\left(L_{\mathrm{n}}-x_{\mathrm{n}}\right) \varepsilon_{\mathrm{n}}+L_{\mathrm{r}} \varepsilon_{\mathrm{r}}\right]=-3600 \frac{|I|}{F}
$$

Because the extent of reaction in the two electrodes is different but concentration is uniform

$$
\frac{C^{*} d\left[\left(L_{\mathrm{p}}-x_{\mathrm{p}}\right) \varepsilon_{\mathrm{p}}\right]}{C^{*} d\left[\left(L_{\mathrm{n}}-x_{\mathrm{n}}\right) \varepsilon_{\mathrm{n}}\right]}=\frac{3-2 t^{+}}{2 t^{+}-1}
$$

Equations 13 and 14 can be integrated to obtain

$$
\frac{x_{\mathrm{p}} \varepsilon_{\mathrm{p}}}{3-2 t^{+}}=\frac{x_{\mathrm{n}} \varepsilon_{\mathrm{n}}}{2 t^{+}-1}=3600\left(t-t_{\mathrm{o}}\right) \frac{|I|}{2 C^{*} F}
$$

Hence, the discharge period is given by

$$
\begin{gathered}
t_{\mathrm{d}}=t_{\mathrm{o}}+t_{\mathrm{f}} \\
=\frac{\left(L_{\mathrm{p}} \varepsilon_{\mathrm{p}}+L_{\mathrm{n}} \varepsilon_{\mathrm{n}}+L_{\mathrm{r}} \varepsilon_{\mathrm{r}}\right)\left(C_{\mathrm{ref}}-C^{*}\right) F}{3600|I|} \\
+\frac{2 C^{*} F}{3600|I|} \min \left(\frac{L_{\mathrm{p}} \varepsilon_{\mathrm{p}}}{3-2 t^{+}} \text {and } \frac{L_{\mathrm{n}} \varepsilon_{\mathrm{n}}}{2 t^{+}-1}\right)
\end{gathered}
$$

The overpotential during this period can be calculated as follows. As electrodes freeze, charge-transfer reactions cannot occur on the icecovered portions of the electrode. Hence, thickness of the active zone of the electrodes decreases. When the depth of the ice layer is $x_{\mathrm{p}}$ in the positive electrode, the thickness of the active zone in it will only be $\left(L_{\mathrm{p}}-x_{\mathrm{p}}\right)$, and it will be $\left(L_{\mathrm{n}}-x_{\mathrm{n}}\right)$ in the negative electrode. Hence, substituting Tafel kinetics in the charge balance $(|I|=S L)$, we get

$$
\frac{|I|}{L_{\mathrm{p}}-x_{\mathrm{p}}}=(a i)_{\mathrm{op}} \frac{C^{*}}{C_{\mathrm{ref}}} \exp \left[\frac{-F\left(\phi_{\mathrm{s}}-\phi-E_{\mathrm{p}}^{o}\right)}{R T_{\mathrm{d}}}\right]
$$

in the positive plate and

$$
\frac{|I|}{L_{\mathrm{n}}-x_{\mathrm{n}}}=(a i)_{\mathrm{on}} \exp \left[\frac{F\left(\phi_{\mathrm{s}}-\phi-E_{\mathrm{n}}^{o}\right)}{R T_{\mathrm{d}}}\right]
$$

in the negative plate. $E^{o}$ is now constant at $C^{*}\left(T_{\mathrm{d}}\right)$.

The decrease in cell potential from its initial value, $\eta$, can be computed from

$$
\begin{aligned}
\eta= & E_{\mathrm{p}}^{o}\left(C_{\mathrm{ref}}\right)-E_{\mathrm{p}}^{o}\left(C^{*}\right)+E_{\mathrm{n}}^{o}\left(C^{*}\right)-E_{\mathrm{n}}^{o}\left(C_{\mathrm{ref}}\right) \\
& +\frac{R T_{\mathrm{d}}}{F}\left(\log \frac{|I|}{(a i)_{\mathrm{on}}\left(L_{\mathrm{n}}-x_{\mathrm{n}}\right)}+\log \frac{|I|}{(a i)_{\mathrm{op}}\left(L_{\mathrm{p}}-x_{\mathrm{p}}\right)} \frac{C_{\mathrm{ref}}}{C^{*}}\right)
\end{aligned}
$$

Equation 20 can be used along with values of $x_{\mathrm{p}}$ and $x_{\mathrm{n}}$ obtained from Eq. 15 to predict $\eta$.

\section{Results and Discussion}

The decrease in the voltage for a hybrid AGM-Gel VRLA battery was observed as a function of time at -20 and $-40^{\circ} \mathrm{C}$. The voltage was divided by six to report it as the average voltage of a cell. The observations are shown by the symbol (+) in Fig. 3 and 4. The cell voltage drops steeply at the very initial stages by nearly $100 \mathrm{mV}$. This supports assumption of validity of Tafel kinetics. The initial drop was used to fit the product $(a i)_{\mathrm{o}}$. It was assumed that it has the same value in the positive and negative electrodes. As expected, values of $(a i)_{0}$ decreased considerably with decreasing temperature They were found to be $1.93 \times 10^{-4} \mathrm{~A} / \mathrm{cm}^{3}$ at $-20^{\circ} \mathrm{C}$ and 1.5 


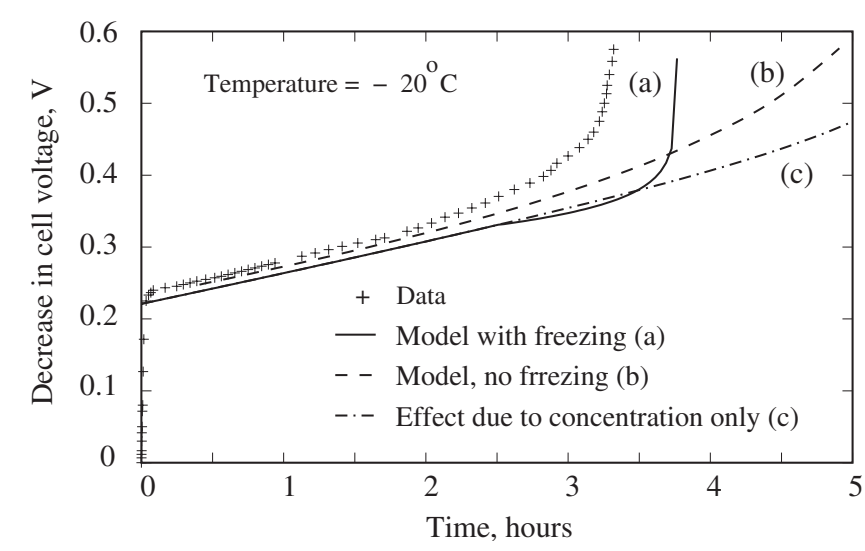

Figure 3. Decrease in cell potential from initial value at $-20^{\circ} \mathrm{C}$ as a function of time.

$\times 10^{-5}$ at $-40^{\circ} \mathrm{C}$. These values were used to make predictions. Thus, the effect of temperature on the charge-transfer reaction is accounted for.

Predictions of the model.- Predictions of the decrease in endcell potential made from Eq. 12 and 20 are shown in Fig. 3 and 4 by curves labeled (a). These account for the freezing phenomena. Predictions assuming that freezing does not occur were made by integrating Eq. 5-7 and Tafel forms of Eq. 4. The finite volume method was used, and resulting nonlinear equations were solved iteratively using BANDJ routine. ${ }^{11}$ These predictions are shown by curves labeled (b) in Fig. 3 and 4. The values of $(a i)_{0}$ used in both models are the same and equal to those mentioned above.

Data in Fig. 3 and 4 show that cell voltage drops by $0.6 \mathrm{~V}$ at $3.5 \mathrm{~h}$ at $-20^{\circ} \mathrm{C}$ and at $2.75 \mathrm{~h}$ at $-40^{\circ} \mathrm{C}$, and that the drop is very steep, indicating arrest of discharge. Curves (b) of Fig. 3 and 4 indicate that predictions made by neglecting freezing show a drop of $0.6 \mathrm{~V}$ in the cell potential at much longer times: at nearly $5 \mathrm{~h}$ at $-20^{\circ} \mathrm{C}$ and at $4.25 \mathrm{~h}$ at $-40^{\circ} \mathrm{C}$. Furthermore, the predicted drop is still not very steep at those times. Clearly, models that neglect freezing are not satisfactory. Because freezing does not occur in the middle cells of the battery, their performance is represented by curves (b). Hence, a point worth noting is that the overpotential contributed by these cells will be much smaller than the observed average value.

Curves (a) in Fig. 3 and 4 show predictions of the decrease in end-cell potential based on inclusion of freezing phenomena. These predictions cannot be compared directly to observations of the average cell potential. However, the steep fall in the average cell po-

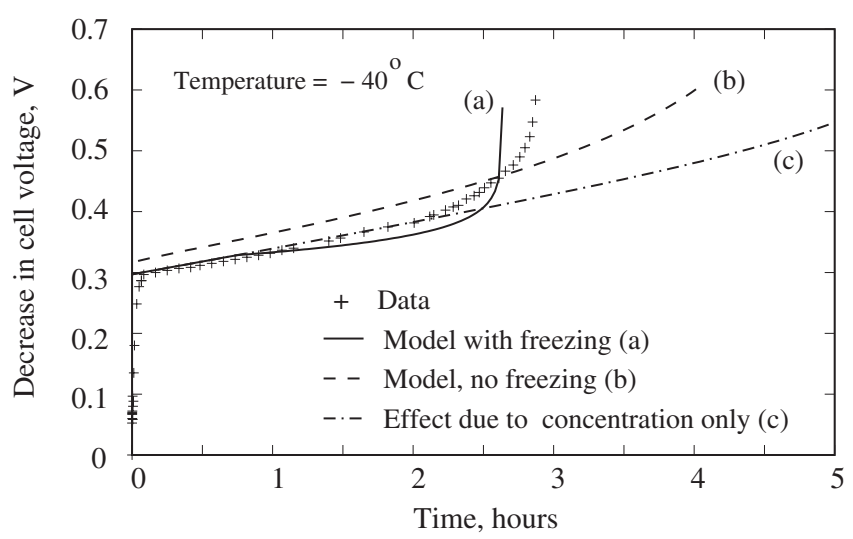

Figure 4. Decrease in cell potential from initial value at $-40^{\circ} \mathrm{C}$ as a function of time.

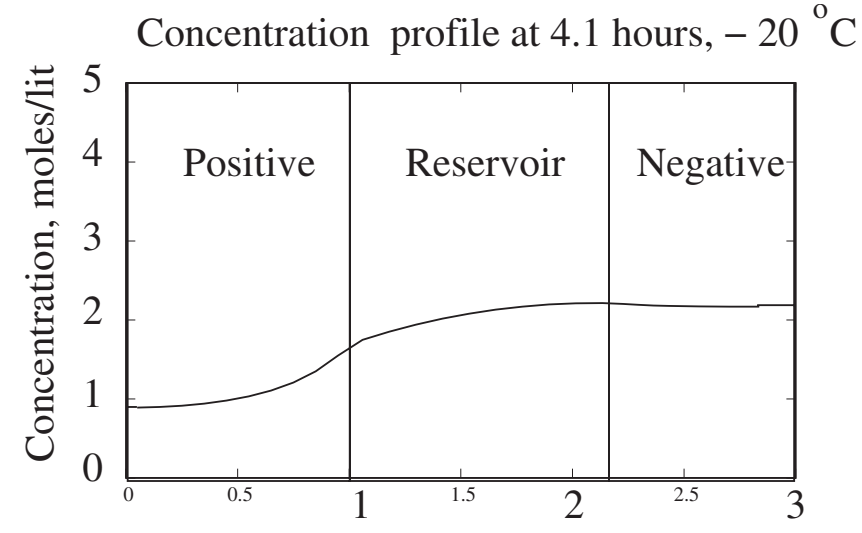

Distance, nondimensional

Figure 5. Concentration profiles in the cell at $-20^{\circ} \mathrm{C}$ at $4.1 \mathrm{~h}$.

tential is controlled by the performance of the outer cells. Therefore, one does expect good agreement between the observations and the model predictions once the drop in voltage is steep. It is seen that the model predicts that the battery will operate for a slightly longer period than observed at $-20^{\circ} \mathrm{C}$ and for a slightly shorter period than observed at $-40^{\circ} \mathrm{C}$. The deviations are of the order of $\sim 20 \mathrm{~min}$ in about a 3-4 h discharge period. The agreement between the observations and predictions is fairly good. The average cell potential should be computed as a weighted mean of the middle and end cells. Predictions of the average cell potential made by using curves (b) for the middle ones and curves (a) for the end cells will produce an agreement only similar to that shown in Fig. 3 and 4.

Further confirmation of freezing is obtained as follows. Figure 5 shows the concentration profile at $4.1 \mathrm{~h}$ at $-20^{\circ} \mathrm{C}$ computed assuming that freezing does not occur. It is observed that the concentration has fallen to nearly 2 moles/L or less everywhere. But, it can be seen from Fig. 1 that at $-20^{\circ} \mathrm{C}$, the electrolyte should freeze at 2.5 moles/L itself. Clearly, the outer cells should freeze. Another feature to be noted is that concentration profiles are not steep at this time, though gradients are not negligible. Concentration profiles at $-40^{\circ} \mathrm{C}$ at $3 \mathrm{~h}$, though not shown, also indicate that the concentrations have fallen below the freezing concentration.

Correlation of discharge capacity data.- The reduction in the discharge period can also be viewed as a reduction in the capacity available for discharge from its full value. Data on reduction in capacity available for discharge as a function of temperature are given in Ref. 8 . In the data, capacity available for discharge at a $20 \mathrm{~h}$ rate and at $25^{\circ} \mathrm{C}$ is taken as the reference. Reduction from this value for discharge at a $20 \mathrm{~h}$ rate and at $-55,-40,-30$, and $-20^{\circ} \mathrm{C}$ are reported as percentage of the capacity at a $20 \mathrm{~h}$ rate and at $25^{\circ} \mathrm{C}$. The data can be read from Fig. 23.19 of Ref. 8 (see Table II). The model presented here can be indirectly tested against the data, assuming that the $20 \mathrm{~h}$ rate corresponds to low current density, as follows. Equation 17 can be rewritten as

Table II. Data on percent capacity of $20 \mathrm{~h}$ rate capacity at $25^{\circ} \mathrm{C}$ as a function of temperature reported in Ref. 8.

\begin{tabular}{lcccc} 
Temperature $\left({ }^{\circ} \mathrm{C}\right)$ & -55 & -40 & -30 & -20 \\
\hline Percentage capacity & 15 & 30 & 50 & 60
\end{tabular}




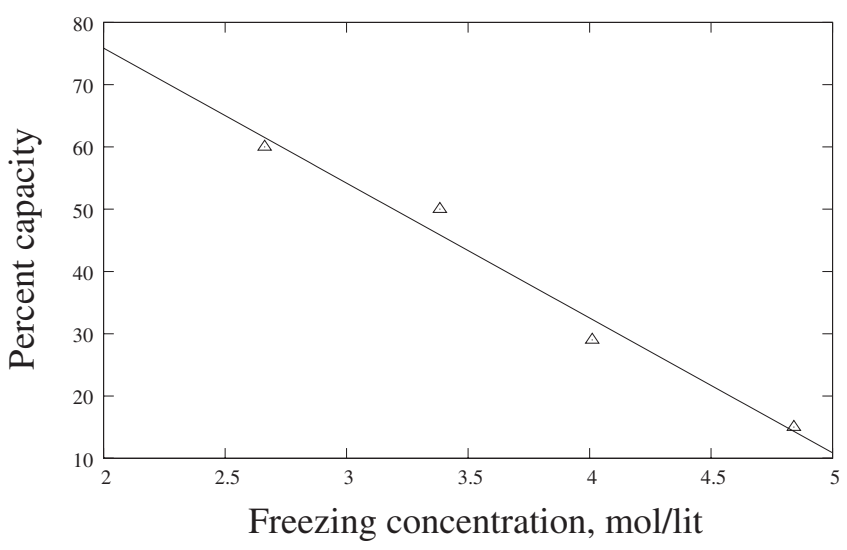

Figure 6. Test of expected correlation of percent capacity against freezing concentration at the discharge temperature.

$$
\begin{aligned}
& \frac{3600 t_{\mathrm{d}}|I|}{\left(L_{\mathrm{p}} \varepsilon_{\mathrm{p}}+L_{\mathrm{n}} \varepsilon_{\mathrm{n}}+L_{\mathrm{r}} \varepsilon_{\mathrm{r}}\right) C_{\mathrm{ref}} F} \\
& =\left(1-\frac{C^{*}}{C_{\mathrm{ref}}}\right)+\frac{C^{*}}{C_{\mathrm{ref}}} \min \frac{1}{L_{\mathrm{p}} \varepsilon_{\mathrm{p}}+L_{\mathrm{n}} \varepsilon_{\mathrm{n}}+L_{\mathrm{r}} \varepsilon_{\mathrm{r}}} \\
& \times\left(\frac{2 L_{\mathrm{p}} \varepsilon_{\mathrm{p}}}{3-2 t^{+}} \text {and } \frac{2 L_{\mathrm{n}} \varepsilon_{\mathrm{n}}}{2 t^{+}-1}\right)
\end{aligned}
$$

$3600 t_{\mathrm{d}}|I|$ is the total amount of charge obtained from the cell during the entire discharge period, and hence, it is the capacity available for discharge at the temperature of experimentation. $\left(L_{\mathrm{p}} \varepsilon_{\mathrm{p}}+L_{\mathrm{n}} \varepsilon_{\mathrm{n}}\right.$ $\left.+L_{\mathrm{r}} \varepsilon_{\mathrm{r}}\right) C_{\mathrm{ref}} F$ is theoretically the maximum discharge capacity. At $25^{\circ} \mathrm{C}$ also, the discharge capacity will be less than this, but will be a fraction of this. Thus, the left-hand side is proportional to the percent of the capacity at $25^{\circ} \mathrm{C}$ that is available for discharge at the temperature of experimentation. Hence, it should be proportional to the percent capacity shown in Table II. The second term on the right-hand side is proportional to the fraction of theoretical capacity left in the electrodes at the time when the first of them freezes. It will be less than $C^{*} / C_{\text {ref. }}$. Hence, the above equation suggests that, at low current density, the percent capacity should correlate as

$$
\text { percentage capacity } \propto-C^{*}\left(T_{\mathrm{d}}\right)
$$

The freezing concentrations, $C^{*}\left(T_{\mathrm{d}}\right)$, at the discharge temperatures shown in Table II were obtained from the phase diagram. Data in Table II can be replotted as percent capacity vs freezing concentration, $C^{*}\left(T_{\mathrm{d}}\right)$, and is shown in Fig. 6 . The data fit a straight line quite satisfactorily. In the absence of battery-design details, the fit shown in Fig. 6 is not a quantitative validation of the model but is indicative of the support to the model. The correlation is of practical value and can be used to make an estimate of percent of discharge capacity at low temperatures.

Temperature increase in cell.- In the model, we have assumed that the temperature in the end cells is uniform and equal to ambient or discharge temperature. The former is a fairly good assumption. However, latent heat has to be removed and this implies that the end cell must be at a higher, though uniform, temperature than the ambient. If the temperature is significantly large, then freezing will be delayed and hence the battery should function for a longer period. We now estimate the effect of this. The latent heat is lost to the ambient from one side and also to the immediately adjoining cell from the other side. For simplicity, we will assume that the adjoining cells are also at the ambient temperature. The heat balance over the end cell is then given by

$$
\frac{d H}{d t}=-2 h\left(T-T_{\mathrm{d}}\right)
$$

where $h$ is the heat transfer coefficient that combines the conductive resistance of the plastic casing and the external convection. In this paper, we neglect the convection resistance. The factor of 2 in Eq. 21 accounts for loss through two plastic walls enclosing the end cells. $H$ is the total enthalpy per unit area and is given by

$$
\begin{aligned}
\frac{H}{6}= & \sum_{i}\left[L_{i}\left(1-\varepsilon_{i}\right) H_{i \mathrm{~s}}+x_{i} \varepsilon_{i} H_{\text {ice }}+\left(L_{i}-x_{i}\right) \varepsilon_{i} H_{\text {fluid }}\right]+L_{\mathrm{r}}\left(1-\varepsilon_{\mathrm{r}}\right) H_{\mathrm{s}} \\
& +L_{\mathrm{r}} \varepsilon_{\mathrm{r}} H_{\text {fluid }}
\end{aligned}
$$

Here $H_{i \mathrm{~s}}$ is the enthalpy of solid phase, $x_{i}$ is the thicknesses of the ice layer, and sum over subscript $i$ represents sum over positive and negative electrodes. $H_{\text {ice }}$ is the enthalpy of ice, and $H_{\text {fluid }}$ is the enthalpy of electrolyte. The factor 6 comes from the fact that there are six pairs of half electrodes and six reservoirs in the cell. We neglect the small contribution made to the enthalpy by an extra negative plate. Substituting Eq. 22 into Eq. 21, we obtain

$$
\begin{aligned}
\sum_{i=\mathrm{p}, \mathrm{r}, \mathrm{n}} L_{i} \frac{d}{d t}\left[\left(1-\varepsilon_{i}\right) H_{i \mathrm{~s}}+\varepsilon_{i} H_{\text {fluid }}\right]= & \sum_{i} \varepsilon_{i} \frac{d}{d t} x_{i}\left(H_{\text {fluid }}-H_{\text {ice }}\right) \\
& -\frac{h}{3}\left(T-T_{\mathrm{d}}\right)
\end{aligned}
$$

Equation 23 indicates that a small increase in temperature of the battery can be expected as freezing proceeds. Note that if $h$ is very large, then the temperature of the cell is equal to $T_{\mathrm{d}}$, which was what was assumed in the previously developed model. Equation 23 can be integrated along with Eq. 13 and 14 by treating $C^{*}$ as a function of $T$ to find $x_{\mathrm{p}}, x_{\mathrm{n}}, T$, and $C^{*}(T)$. Overpotential of the end cells can be computed using Eq. 20. It was found that the temperature rise is of the order of $4^{\circ}$ when the discharge or ambient temperature is $-20^{\circ} \mathrm{C}$ and $2^{\circ}$ when the discharge or ambient temperature is $-40^{\circ} \mathrm{C}$. The thickness of the electrode that freezes fully is the same at all temperatures. Thus, the latent heat to be removed is also the same. When current density is constant, the time required for an electrode to freeze, $t_{\mathrm{f}}$, is proportional to the acid concentration at freezing condition (see Eq. 17). Hence, freezing begins at a lower acid concentration at a higher discharge temperature. Hence, the rate of freezing, and thereby the rate of liberation of latent heat, is greater at $-20^{\circ} \mathrm{C}$ than at $-40^{\circ} \mathrm{C}$. It is for this reason that a larger temperature difference is required for freezing to proceed at higher discharge temperatures. As a result of the increase in the temperature, freezing can occur until a concentration lower than $C^{*}\left(T_{\mathrm{d}}\right)$ is reached. However, the lowering is not significant and the battery functions for nearly the same period. The results of calculation of decrease in cell potential that take into account the temperature rise are compared in Fig. 7 with those that neglect it. It can be seen that the error is marginal, the difference being only in predictions of the overpotential.

Prolonging the discharge period.- The model suggests that discharge is arrested due to freezing, and the discharge period can be prolonged if it can be prevented or delayed. The above calculation suggests a way to do this. If heat loss to the ambient is reduced, then the latent heat is utilized to raise the temperature of the battery. Consequently, freezing is delayed and the discharge period is increased. Increasing insulation thickness is a possible way, but a constraint is a large increase in the volume of the battery. It does require superior insulating materials to keep the battery size sufficiently small in order to use this strategy.

Applicability of model.- Applicability of the model depends on the validity of the various assumptions, and we examine these.

Ohmic and diffusional resistances. - In the following, we use $L_{\mathrm{c}}$ $=L_{\mathrm{p}}$ or $L_{\mathrm{n}}$ as dictated by context. The parameter $(a i)_{\mathrm{o}} L /|I|$ was found to be 0.1 at $-20^{\circ} \mathrm{C}$ itself, and hence, use of Tafel kinetics is 


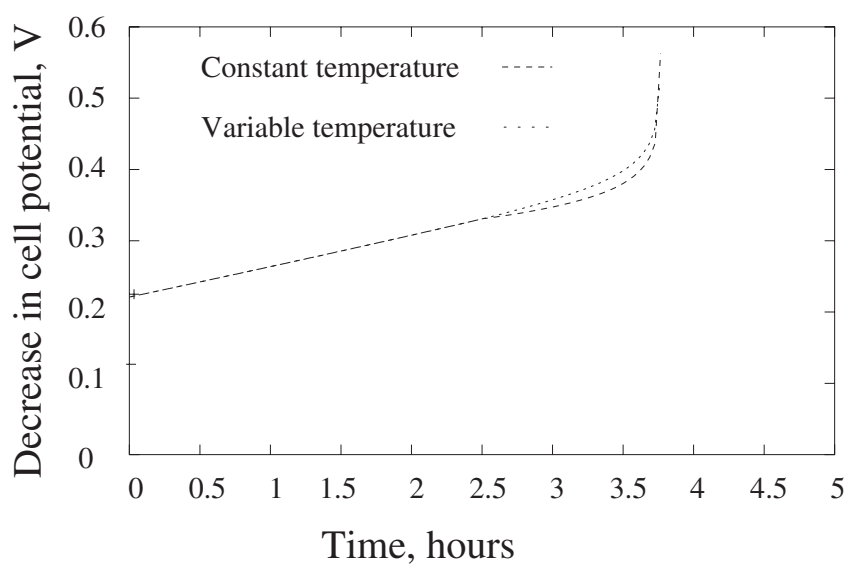

Figure 7. Effect of neglect of temperature rise on the overpotential of the cell at ambient temperature of $-20^{\circ} \mathrm{C}$.

justified. The parameter $(a i)_{\mathrm{o}} L^{2}(F / R T)[(1 / \mathrm{\kappa})+(1 / \sigma)]$ has been calculated to be of the order of $10^{-4}$. Thus, one part of the condition for assessing smallness of ohmic losses is satisfied. However, the parameter $L|I|(F / R T)[(1 / \kappa)+(1 / \sigma)]$ has been found to be of the order of 0.25 . The ohmic resistance is negligible, but not by a large margin. Pavlov ${ }^{12}$ as well as Bullock and Vincent ${ }^{13}$ report that the open-circuit voltage $(\mathrm{OCV})$ of the cell drops by only $\sim 0.2 \mathrm{~V}$ as the acid concentration decreases during discharge. The decrease in the cell voltage due to the decrease in the acid concentration can be accounted for by using expressions given by Bode. ${ }^{9}$ The decrease in cell voltage can be predicted by adding it to the drop due to charge transfer. Such a prediction is shown by curves labeled (c) in Fig. 3 and 4. It is seen that curves (b) are parallel to curves (c), but differ by a small extent. It can be concluded that the initial linear decrease in cell voltage is almost entirely due to a decrease in the concentration of the acid and consequent decrease in the equilibrium potential. The small deviations can be attributed to neglect of ohmic resistance, justifying this assumption.

At $-40^{\circ} \mathrm{C}$, the parameter $f|I| L / F D_{\text {eff }} C_{\text {ref }}$ was found to be 0.1 for the negative and 0.6 in the positive. The diffusion resistance in the negative is negligible, while it is not so in the positive. Computed concentration profiles shown in Fig. 5 also confirm this. As concentration decreases with discharge time, the penetration depth will increase and approach the electrode thickness. However, the effective thickness of the electrode also decreases as the thickness of the frozen layer increases. These two are opposing effects, and it is difficult to forecast the combined effect. However, we feel that the major cause for the deviations between predictions of the model and observations is the neglect of diffusion resistance. However, here it may be relevant to draw attention to the interesting observations made by Willinganz ${ }^{14}$ during discharge at low temperatures. He investigated the causes of inhibition of charging at low temperatures. In the course of his investigations, he found that crystals of lead sulfate formed during discharge become more fine grained as the temperature is decreased. It is possible that the size of the crystals may also affect characteristics of discharge and freezing.

Order of reaction.- The order of the reaction assumed for the kinetics also does not have too much influence on the discharge period because it is determined by the freezing concentration (see Eq. 17). The overpotential at a given concentration is determined by the order of the reaction as can be seen from Eq. 12 and 20. Using an order of 0.3 instead of 1 in the positive will reduce the overpotential while using 1 instead of 0 in the negative will increase it.

Effect of current density.- We have considered a fairly low current density. As current density is increased, several of the assumptions become invalid. It is clear that diffusion resistance and, hence, concentration gradients cannot be neglected. Under these conditions, the diffusion equation has to be solved and this will lead to a moving boundary value problem. Moreover, the rate of heat release will be greater at higher current densities and it is possible that temperature gradients in the cell as well as in the battery cannot be neglected. Freezing will however still begin in the outer cells and proceed symmetrically from the center of each electrode in each cell, but under the influence of concentration and temperature gradients. Here, freezing can be expected to begin earlier because concentration will decrease to a greater extent in the center of the electrodes when diffusion resistances are important. It can be expected that the battery will function for a lesser duration. The results of the model presented here by assuming that discharge is controlled by the rate of the charge-transfer reaction can be considered as the upper bound for an estimate of the discharge periods.

Relevance to other battery systems. - There are other battery systems that employ conducting electrolytes, for example, lithium-ion batteries. Concentration gradients of salt can be established (for example, see Verbrugge et al. ${ }^{15}$ ) during the functioning of the battery, and it is possible that these batteries also can freeze at low temperatures as dictated by the phase diagram. Some of the features of the present work will be relevant to develop a model of this phenomenon in lithium batteries.

\section{Conclusions}

A simplified model has been developed to predict the discharge times of a lead-acid battery at very low temperatures $\left(<-20^{\circ} \mathrm{C}\right)$. The model is valid where Tafel kinetics are applicable and ohmic losses and diffusion limitations are absent, and where the thermal resistance to heat loss is in the casing of a battery and in the external convection. At very low temperatures, discharge of the battery is arrested when the electrolyte freezes. It occurs when the acid concentration falls to that corresponding to the freezing condition at the discharge temperature. The model proposes that freezing starts in the middle of electrodes and proceeds toward the reservoir, and the battery stops discharging when one of the electrodes freezes fully. The model gives a simple equation to predict the discharge time. The predictions of the model are in good agreement at observations made at -20 and $-40^{\circ} \mathrm{C}$ and at low current density. The moving boundary value problem must be solved to account for diffusion limitations, which will become important at high current densities.

\section{Acknowledgments}

We thank Professor D. Pavlov and Dr. Alok K. R. Paul for a critical reading of the article and many helpful discussions. We thank Professor R. Kumar for valuable comments on the article. We also thank Anil Jain, Managing Director, NED Energy Ltd., for constant encouragement and support. We acknowledge financial support from DRDO, India.

Indian Institute of Science assisted in meeting the publication costs of this article.

\section{Appendix}

Operational and dimensional details of the battery.-Half thicknesses of the electrode are $L_{\mathrm{p}}=0.155 \mathrm{~cm}, L_{\mathrm{r}}=0.185 \mathrm{~cm}$, and $L_{\mathrm{n}}=0.105 \mathrm{~cm}$. Width $=15.2 \mathrm{~cm}$, height $=11.6 \mathrm{~cm}$. Initial porosities of the battery are $\varepsilon_{\mathrm{p}}=0.6, \varepsilon_{\mathrm{r}}=0.94$, and $\varepsilon_{\mathrm{n}}=0.6$. $|I|=0.0068 \mathrm{~A} / \mathrm{cm}^{2}$ corresponding to $\mathrm{C} / 5$.

Physical property data used.-Conductivity of aq. $\mathrm{H}_{2} \mathrm{SO}_{4}$ was given by Newman and Tiedemann and is quoted by Gu et al. ${ }^{16}$ in units of $\mathrm{S} / \mathrm{cm}$

$$
\kappa=C \exp \left(1.1104+199.475 C-16097.781 C^{2}+\frac{3916.95}{T}-\frac{99406}{T} C-\frac{712860}{T^{2}}\right)
$$

Diffusivity of acid in aq. $\mathrm{H}_{2} \mathrm{SO}_{4}$ in units of centimeters squared per second given by Newman and Tiedemann and is quoted by Gu et al. ${ }^{16}$

$$
D=(1.75+260 C)\left(10^{-5}\right) \exp \left(\frac{2174.0}{298.15}-\frac{2174.0}{T}\right)
$$

$D_{\text {eff }}$ is given by the Bruggeman-type relationship: $D_{\text {eff }}=\varepsilon^{1.5} D$. Expressions for equilibrium potential properties were taken from Bode

$E^{o}$ Positive $=1.62814+0.073924 \log m+0.03312(\log m)^{2}+0.04322(\log m)^{3}$ $+0.021567(\log m)^{4}$ 


\begin{tabular}{|c|c|c|}
\hline Property & Value & Ref. \\
\hline$\sigma$ of $\mathrm{PbO}_{2}$ & $500 \mathrm{~S} / \mathrm{cm}$ & 9 \\
\hline$\sigma$ of $\mathrm{Pb}$ & $4.8 \times 10^{4} \mathrm{~S} / \mathrm{cm}$ & 9 \\
\hline Density of $\mathrm{PbO}_{2}$ & $9.8 \mathrm{~g} / \mathrm{cm}^{3}$ & 9 \\
\hline Density of $\mathrm{Pb}$ & $11.3 \mathrm{~g} / \mathrm{cm}^{3}$ & 9 \\
\hline $\begin{array}{l}\text { Density of acid, } \\
\text { initial value }\end{array}$ & $1.25 \mathrm{~g} / \mathrm{cm}^{3}$ & 9 \\
\hline$C_{p}$ of $\mathrm{PbO}_{2}$ & $0.27 \mathrm{~kJ} /(\mathrm{kg} \mathrm{K})$ & 9 \\
\hline$C_{p}$ of $\mathrm{Pb}$ & $0.13 \mathrm{~kJ} /(\mathrm{kg} \mathrm{K})$ & 9 \\
\hline $\begin{array}{l}C_{p} \text { of acid, average value } \\
\text { was used }\end{array}$ & $3.5 \mathrm{~kJ} /(\mathrm{kg} \mathrm{K})$ & 9 \\
\hline $\begin{array}{l}\text { Thermal conductivity } \\
\text { of } \mathrm{PbO}_{2}\end{array}$ & $0.03 \mathrm{~W} /(\mathrm{cm} \mathrm{K})$ & 5 \\
\hline $\begin{array}{l}\text { Thermal conductivity } \\
\text { of } \mathrm{Pb}\end{array}$ & $0.33 \mathrm{~W} /(\mathrm{cm} \mathrm{K})$ & 5 \\
\hline $\begin{array}{l}\text { Thermal conductivity } \\
\text { of acid }\end{array}$ & $0.005 \mathrm{~W} /(\mathrm{cm} \mathrm{K})$ & 5 \\
\hline $\begin{array}{l}\text { Thermal conductivity } \\
\text { of polypropylene }\end{array}$ & $0.00117 \mathrm{~W} /(\mathrm{cm} \mathrm{K})$ & Appendix $\mathrm{C}$ in 17 \\
\hline $\begin{array}{l}\text { Transference number } \\
\text { of } \mathrm{H}^{+}, t^{+}\end{array}$ & 0.72 & 1 \\
\hline \multicolumn{3}{|c|}{$E^{o}$ Negative $=-0.2946-0.073595 \log m-0.030531(\log m)^{2}-0.030552(\log m)^{3}$} \\
\hline \multicolumn{3}{|c|}{$-0.012045(\log m)^{4}$} \\
\hline \multicolumn{3}{|c|}{ 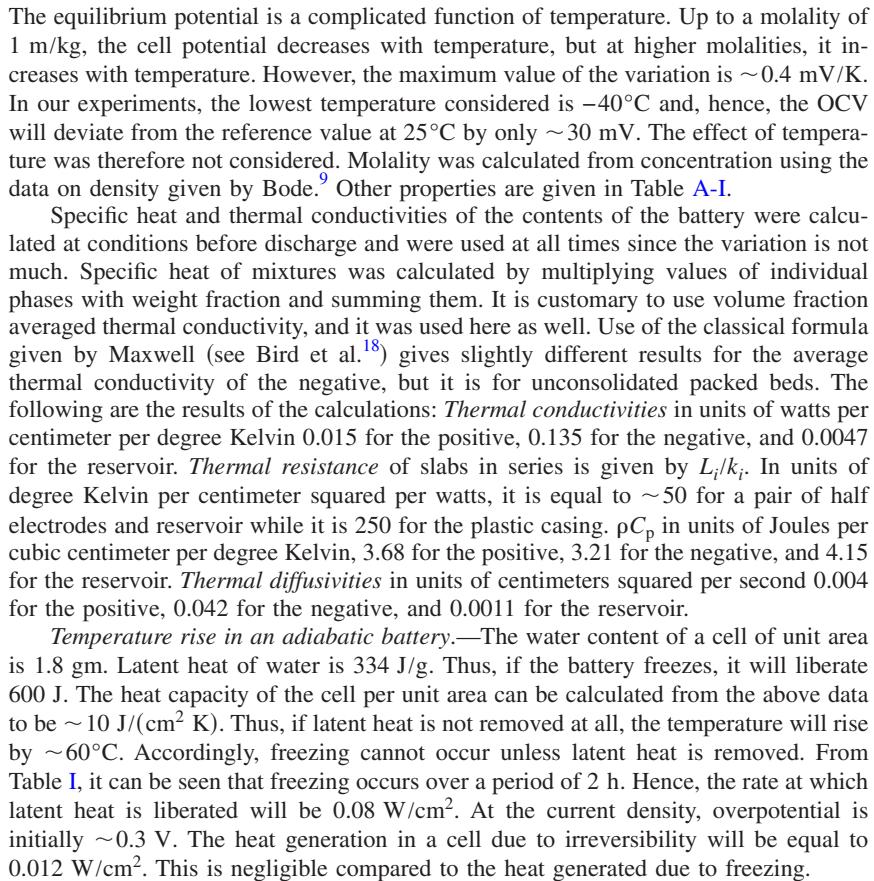 } \\
\hline
\end{tabular}

\section{List of Symbols}

$a$ active surface area per unit volume, $\mathrm{cm}^{-1}$. Subscript $o$ stands for initial state

$C$ concentration of acid, $\mathrm{mol} / \mathrm{cm}^{3}$. Subscript "ref" stands for initial condition

$C^{*}$ equilibrium concentration at freezing conditions, $\mathrm{mol} / \mathrm{cm}^{3}$

$C_{p}$ specific heat, $\mathrm{J} /(\mathrm{g} \mathrm{K})$

$D$ diffusivity of acid, $\mathrm{cm}^{2} / \mathrm{s}$. Subscript "eff" is for effective diffusivity in the porous medium

$E^{o}$ electrode potential at the reference conditions, $V$

$F$ Faraday's constant, coulomb/mol

$H$ enthalpy, J/mol. Subscript "ice" for ice, "fluid" for electrolyte phase, $s$ for electrode phase.

$h$ heat transfer coefficient, $\mathrm{W} /\left(\mathrm{cm}^{2} \mathrm{~K}\right)$

$i_{o}^{\text {ref }}$ exchange current density at $C_{\mathrm{ref}}, \mathrm{A} / \mathrm{cm}^{2}$

$|I|$ current density, $\mathrm{A} / \mathrm{cm}^{2}$

$k$ thermal conductivity, $\mathrm{W} /(\mathrm{cm} \mathrm{K})$

$K_{2}$ equivalence between charge transferred and moles reacted

$L$ thickness, $\mathrm{cm}$

$m$ molality of acid, $\mathrm{mol} / \mathrm{kg}$

$R$ gas constant, $\mathrm{J} /(\mathrm{mol} \mathrm{K})$

$S$ rate of charge-transfer reaction, $\mathrm{A} / \mathrm{cm}^{3}$

$t$ time, $\mathrm{h}$

$t_{\mathrm{d}} \quad$ discharge period, $\mathrm{h}$

$t_{\mathrm{f}}$ time needed for freezing, $\mathrm{h}$

$t_{\mathrm{o}}$ time needed for freezing to begin, $\mathrm{h}$

$t^{+}$transference number of $\mathrm{H}^{+}$

$T$ temperature, $\mathrm{K}$

$T_{\mathrm{d}}$ discharge temperature, $\mathrm{K}$

$x$ thickness of ice layers, $\mathrm{cm}$. Also for coordinate

Greek

$\varepsilon$ porosity

$\kappa_{\text {eff }}$ electrolytic conductivity, $\mathrm{S} / \mathrm{cm}$

$\sigma_{\text {eff }}$ electronic conductivity, $\mathrm{S} / \mathrm{cm}$

$\phi_{s}$ electric potential in electrode, $V$

$\phi$ electric potential in electrolyte, $V$

$\eta$ decrease in cell potential from its initial value, $V$

Subscripts

$$
\begin{array}{cl}
\mathrm{p} & \text { positive electrode } \\
\mathrm{r} & \text { acid reservoir } \\
\mathrm{n} & \text { negative electrode } \\
\mathrm{c} & \text { characteristic value }
\end{array}
$$

\section{References}

1. H. Gu, T. V. Nguyen, and R. E. White, J. Electrochem. Soc., 134, 2953 (1987)

2. T. V. Nguyen and R. E. White, Electrochim. Acta, 38, 935 (1993).

3. E. C. Dimpault-Darcy, T. V. Nguyen, and R. E. White, J. Electrochem. Soc., 135, 278 (1988).

4. D. M. Bernardi, H. Gu, and A. Y. Schoene, J. Electrochem. Soc., 140, 2250 (1993)

5. H. Huang and T. V. Nguyen, J. Electrochem. Soc., 144, 2062 (1997).

6. D. M. Bernardi and M. K. Carpenter, J. Electrochem. Soc., 142, 2631 (1995).

7. J. Newman and W. Tiedemann, J. Electrochem. Soc., 144, 3081 (1997)

8. D. Linden and T. B. Reddy, Handbook of Batteries, Chap. 23, McGraw-Hill, New York (2002).

9. H. Bode, Lead-Acid Batteries, John Wiley \& Sons, Hoboken, NJ (1977).

10. J. Newman and W. Tiedemann, AIChE J., 21, 25 (1975).

11. J. Newman and K. E. Thomas-Alyea, Electrochemical Systems, 3 ed., p. 611, John Wiley \& Sons (2004)

12. D. Pavlov, Essentials of Lead-Acid Batteries, p. 4, Society for Advancement of Electrochemical Science and Technology, Karaikudi, India (2006).

13. K. R. Bullock and C. A. Vincent, Modern Batteries, C. A. Vincent and B. Scrosati, Editors, Chap.5, Arnold, London (1997).

14. E. Willinganz, Power Sources 5, D. H. Collins, Editor, p. 43, Academic Press, New York (1975).

15. M. W. Verbrugge, D. R. Baker, and B. J. Koch, J. Power Sources, 110, 295 (2002).

16. W. B. Gu, C. Y. Wang, and B. Y. Liaw, J. Electrochem. Soc, 144, 2053 (1997).

17. C. A. Harper, Handbook of Plastics, Elastomers \& Composites, McGraw-Hill, New York (1996).

18. R. B. Bird, W. E. Stewart, and E. N. Lightfoot, Transport Phenomena, 2nd ed., John Wiley \& Sons, Hoboken, NJ (2002) 